\title{
Climate regime shifts and reorganization of fish communities: the essential fatty acid limitation hypothesis
}

\author{
Michael A. Litzow ${ }^{1, *}$, Kevin M. Bailey ${ }^{2}$, Fredrick G. Prahl ${ }^{3}$, Ron Heintz ${ }^{4}$ \\ ${ }^{1}$ Alaska Fisheries Science Center, National Marine Fisheries Service, 301 Research court, Kodiak, Alaska 99615, USA \\ ${ }^{2}$ Alaska Fisheries Science Center, National Marine Fisheries Service, 7600 Sand Point Way NE, Seattle, Washington 98115, USA \\ ${ }^{3}$ College of Oceanic and Atmospheric Sciences, Oregon State University, 104 COAS Administration Building, Corvallis, \\ Oregon 97331, USA \\ ${ }^{4}$ Alaska Fisheries Science Center, National Marine Fisheries Service, 11305 Glacier Highway, Juneau, Alaska 99801, USA
}

\begin{abstract}
Climate regime shifts force fish communities through rapid transitions between alternate species assemblages, but little is known about the role that biochemical ecology plays in these transitions. We document a biochemical effect of climate-induced community transitions in boreal oceans: opposite population trajectories of lipid-rich and lipid-poor fish species. We compared published estimates of fish lipid content and population trajectories following climate shifts in 4 areas (Bering Sea, Gulf of Alaska, Scotian Shelf and North Sea). In all cases, total lipid content differed between species that increased and decreased in abundance, and the resulting relatively lipid-rich or lipid-poor communities persisted for decades. We hypothesize that these changes in fish community lipid content are the result of climate-mediated changes in the availability of essential fatty acids (EFAs), which are required by fish as components of hormones and cell membranes. EFAs are produced only by plants and must be obtained by fish through their diet, and ecosystem EFA availability is sensitive to physical forcing mechanisms. Using original data from 5 species of northeast Pacific fish (total lipid 1.0 to $28.9 \%$ wet mass) and published data for 29 species of myctophids (total lipid 0.5 to $46.3 \%$ wet mass), we found that the content of 2 important EFAs was positively correlated with total lipid content. This result suggests the possibility of species differences in EFA requirements that are related to total lipid content, and possible differences in susceptibility to changing EFA availability in lipid-rich and lipid-poor fish species.
\end{abstract}

KEY WORDS: Regime shift - Essential fatty acid · Climate $\cdot$ Community ecology $\cdot$ Lipid

Resale or republication not permitted without written consent of the publisher

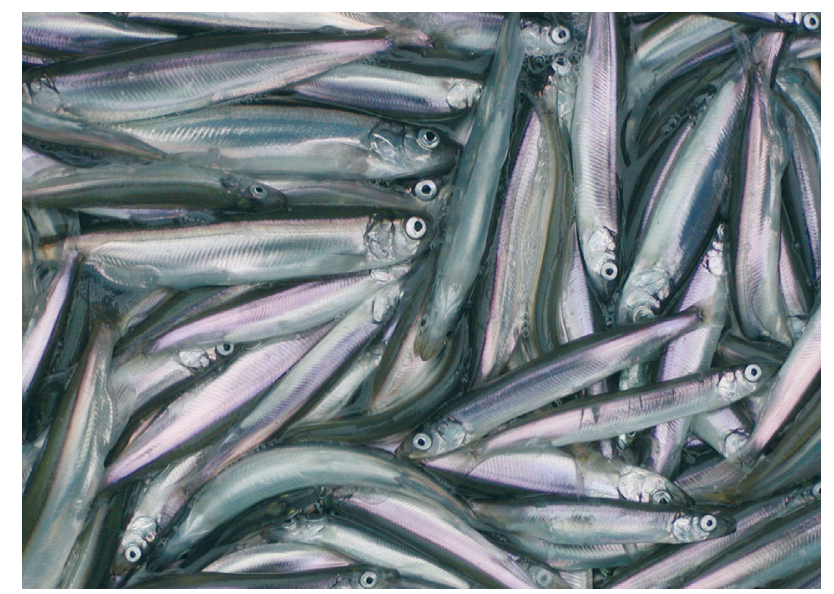

Following the 1970s Pacific Decadal Oscillation regime shift, walleye pollock Theragra chalcogramma, a lipid-poor species, increased in abundance, while capelin Mallotus villosus (photo), a lipid-rich species, declined. The hypothesis is proposed that changes in the availability of essential fatty acids contribute to regime shift effects on fish populations.

Photo: Mayumi Arimitsu

\section{INTRODUCTION}

Continental shelf communities are susceptible to rapid reorganizations separating decadal-scale periods of relative stability. These community transitions involve temporally coherent change at multiple trophic levels on a basin-wide spatial scale (Chavez et al. 2003). Over-fishing is the dominant cause in some instances (Choi et al. 2004), but community transitions 
often follow shifts between decadal-scale climate regimes, and a causal link between climate regime shifts and reorganization in shelf ecosystems is widely accepted, although the processes involved remain mysterious (Anderson \& Piatt 1999, Beaugrand 2004). Proposed hypotheses include changes in the strength of bottom-up and top-down control (Mueter \& Norcross 2000, Hunt et al. 2002) and temporal mis-matches between food supply and early feeding of fish larvae (Anderson \& Piatt 1999).

One of the best-documented patterns of transitions in boreal continental shelf communities is the phenomenon of opposite population trajectories in pelagic and demersal fish species. In a variety of areas in the boreal Pacific and Atlantic Oceans (i.e. Bering Sea, Gulf of Alaska, North Sea, Scotian Shelf), community transitions have resulted in general increases in populations of pelagic species and general decreases in populations of demersal species, or vice versa (Cushing 1980, Anderson \& Piatt 1999, Hunt et al. 2002, Choi et al. 2004). Although this pattern is fairly well recognized, the consequences in terms of community lipid content have received less attention. Shifts between pelagic and demersal species have implications for community lipid content and lipid availability for higher predators, as pelagic fishes are typically richer in lipids than demersal species (Anthony et al. 2000, Iverson et al. 2002). This situation is recognized in the Gulf of Alaska, where a climate regime shift in the 1970s resulted in population decreases in lipid-rich pelagic species (capelin Mallotus villosus and Pacific herring Clupea pallasii) and steady population increases in lipid-poor gadids and pleuronectids (Anderson \& Piatt 1999, Mueter \& Norcross 2000). The resulting low-lipid state has persisted for approximately $20 \mathrm{yr}$ and is hypothesized to have had negative effects on piscivores in the region (Anderson \& Piatt 1999). We are not aware of any study that has sought to determine whether this situation is representative of a larger phenomenon; that is, whether climate regime shifts commonly drive boreal fish communities between lipid-rich and lipidpoor states.

In this paper we document a widespread pattern of opposite population-level responses to community transitions by lipid-rich and lipid-poor fishes, and we propose the hypothesis that climate-mediated change in essential fatty acid (EFA) production by phytoplankton is a mechanism contributing to this pattern ('EFA limitation hypothesis'). Our hypothesis builds on the growing awareness that EFA availability may influence trophic structure in aquatic ecosystems (Brett \& Müller-Navarra 1997). EFAs are nutritionally critical lipid components that cannot be synthesized in appreciable quantities by animals and therefore must be obtained through their diet. Two EFAs, eicosapen- taenoic acid (EPA) and docosahexaenoic acid (DHA), are most commonly identified as limiting in fish (Tocher 2003). EPA and DHA are required for proper cell membrane function, with DHA being particularly important in cell membranes of neural tissues, and as precursors for eicosanoids, a class of hormones (Tocher 2003). EFA restriction results in a variety of ill effects in fish, including decreased fecundity and reduced embryonic viability, impaired growth and decreased survival of early life-history stages, improper pigmentation, impaired vision and inability to feed at low light intensity, impaired ontogeny of behavior such as schooling, and decreased membrane function at low temperatures (Tocher 2003). Because EFA are produced in appreciable quantities in pelagic ecosystems only by phytoplankton and are transferred up food webs, EFA availability to fish is tightly regulated by bottom-up processes (Ahlgren et al. 1996, Dalsgaard et al. 2003).

The EFA limitation hypothesis postulates effects of EFA restriction on fish that are incompletely understood. Most knowledge about fish EFA requirements comes from aquaculture studies using dietary EFA levels far below those found in nature (Dalsgaard et al. 2003), and little is known about the effects of natural EFA variability on fish or species differences in EFA requirements. Lipid-rich species might be expected to contain more EFAs, which suggests an intuitively appealing link between lipid content and EFA requirements. However, EPA and DHA are most prevalent in structural phospholipids (Dalsgaard et al. 2003), while variability among species in total lipid content is largely a function of the content of EFA-poor neutral lipids (Olsen 1999). Lipid content may therefore not correlate with the content of the most critical EFA. Furthermore, comparative data on species EFA content are not readily available. Most papers on the fatty acid content of fish present data on relative fatty acid content ( $\%$ of total fatty acid mass), without giving data on the total mass of fatty acids, and these data cannot be used to derive comparative data on the absolute fatty acid content (\% body mass) of different fish species (Reinhardt \& Van Vleet 1986, Olsen 1999). Developing comparable data on absolute fatty acid content is therefore an important first step in evaluating the potential role of EFA availability in structuring fish communities.

The goals of our research were to (1) test for opposing population-level responses in lipid-rich and lipidpoor fish species following climate regime shifts, and (2) test for correlation between total lipid content and the content of EPA and DHA in order to make inferences about different EFA requirements of lipid-rich and lipid-poor fishes. We used published data on fish lipid content and population trends following climate 
regime shifts to achieve the first goal. For the second goal, we used original data on the EFA content and lipid content of 5 ecologically important fishes from the northeast Pacific as well as published data on myctophids from a variety of habitats. We also briefly review existing knowledge of EFA function in aquatic ecosystems as it pertains to the EFA limitation hypothesis.

\section{MATERIALS AND METHODS}

Lipid content and population trajectories. We searched the Science Citation Index Expanded database for the period 1980 to 2004 for situations where (1) sudden and dramatic changes in fish communities have been linked with persistent, decadal-scale shifts in physical parameters, and (2) changes in fish communities have been documented by standardized trawl surveys that provide trend data for both pelagic and demersal species. We made no attempt to restrict the geographic area of our search, but the 7 studies we found dealt with 4 boreal ecosystems $\left(43^{\circ} \mathrm{N}\right.$ to $61^{\circ} \mathrm{N}$; Table 1). Comparable data on the magnitude of abundance changes could not typically be extracted from published sources, so we simply categorized the abundance of each species as 'increasing' or 'decreasing'.

We were able to find published lipid content data for most of the common species involved in the 4 community reorganizations. Lipid content is highly variable within species due to factors such as age, sex, reproductive status and seasonal variability in energy budgets (Anthony et al. 2000, Iverson et al. 2002). In order to generate data suitable for inter-species comparisons, we averaged every adult value for each species within a given study and then generated species values as the grand mean of various study means (Table 2). We also generated average values for 3 demersal families (Gadidae, Pleuronectidae and Stichaeidae) to use for species for which published lipid data were not available. Lipid content is fairly constant within demersal families (Anthony et al. 2000, Iverson et al. 2002) sug- gesting that these average values were representative. Following Iverson et al. (2001), we corrected lipid data derived using the Bligh \& Dyer method for comparison with the Folch method, using the equation:

$\log ($ Folch $)=0.047+1.122 \times \log ($ Bligh \& Dyer $)$

Because we tested the null hypothesis of no relationship between lipid content and population trajectory 4 times (once in each ecosystem), we maintained the expected type-I error rate at $5 \%$ of all significant results by using false discovery rate control, which adjusted individual $\alpha$ values for the 4 tests (Verhoeven et al. 2005).

Total lipid and EFA content. We tested for correlations between total lipid and EFA content with data from a group of northeast Pacific fish species (Pacific sand lance Ammodytes hexapterus, capelin Mallotus villosus, Pacific herring Clupea pallasii, Pacific hake Merluccius productus and walleye pollock Theragra chalcogramma). Fish were collected quarterly with a mid-water rope trawl from 2 locations in southeastern Alaska in 2001 and 2002, and were flash-frozen in liquid nitrogen and stored at $-80^{\circ} \mathrm{C}$ prior to analysis. Lipid was extracted in Folch reagent with BHT to prevent oxidation from whole homogenized fish using a Dionex Accelerated Solvent Extractor. After extraction, filtrate was washed with $0.88 \% \mathrm{KCl}$ followed by a solution of methanol/deionized water (1:1 v:v) in volumes equal to $25 \%$ of the extract volume. Excess solvent was evaporated under nitrogen to a volume of $1.0 \mathrm{ml}$ and the lipid content of a $0.5 \mathrm{ml}$ aliquot was determined gravimetrically. Lipid samples were stored under nitrogen to minimize oxidation. Duplicate sample results were reproducible to within $15 \%$ and analysis of National Institute for Standards and Technology standard reference material 1946 by this method is within $5 \%$ of the published value.

In order to capture seasonal variability in EFA content, we analyzed EFA content during the sampling periods of minimum and maximum lipid content for each species, with the exception of Pacific sand lance, which was collected during a single month. The fatty acid

Table 1. Climate regime shifts used to test for alternate lipid states in fish comunities

\begin{tabular}{|c|c|c|c|c|c|}
\hline Region & $\begin{array}{c}\text { Time of } \\
\text { shift }\end{array}$ & $\begin{array}{c}\text { Temperature } \\
\text { change }\end{array}$ & $\begin{array}{c}\text { Pelagic species } \\
\text { change }\end{array}$ & $\begin{array}{c}\text { Demersal species } \\
\text { change }\end{array}$ & Source \\
\hline Bering Sea & $1970 \mathrm{~s}$ & Increase & Decrease & Increase & Hunt et al. (2002) \\
\hline Gulf of Alaska & $1970 \mathrm{~s}$ & Increase & Decrease & Increase $^{\mathrm{a}}$ & Anderson \& Piatt (1999), Mueter \& Norcross (2000) \\
\hline North Sea & $1960 \mathrm{~s}$ & Decrease & Decrease & Increase & Cushing $(1980,1984)$, Beaugrand (2004) \\
\hline Scotian Shelf & $1980 \mathrm{~s}$ & Decrease & Increase & Decrease & $\begin{array}{l}\text { Choi et al. (2004) } \\
\text { Department of Fisheries } \\
\text { and Oceans (various) }\end{array}$ \\
\hline
\end{tabular}


Table 2. Lipid content ( $\%$ wet mass, mean \pm SE) of fishes used to test for alternate lipid states in fish communities following climate regime shifts. When more than one source was available for a species, average of study values was used in analysis. Family averages for Gadids, flatfish, sculpins and pricklebacks included grand means of individual species means for every species included in the cited sources. $\mathrm{n}=$ number of studies for species estimates or number of species for family estimates. 1: Anthony et al. (2000); 2: Budge et al. (2002); 3: R. Foy, University of Alaska, pers. comm.; 4: Heintz et al. unpubl. data; 5: Iverson et al. (2002); 6: Kirsch et al. (1998); 7: Lawson et al. (1998); 8: Logerwell \& Schauffler (2005); 9: Payne et al. (1999); 10: Vollenweider (2005); 11: Worthy \& Miculka (1997)

\begin{tabular}{|c|c|c|c|c|}
\hline Common name & Scientific name & Lipid content & $\mathrm{n}$ & Source \\
\hline \multicolumn{5}{|l|}{ Demersal } \\
\hline American plaice & Hippoglossoides platessoides & $2.6 \pm 0.4$ & 2 & 2,7 \\
\hline Atka mackerel & Pleurogrammos monopterygius & $8.9 \pm 2.0$ & 2 & 4,8 \\
\hline Arrowtooth flounder & Atheresthes stomias & $6.8 \pm 0.9$ & 2 & 3,4 \\
\hline Cod & Gadus morhua & $2.4 \pm 0.3$ & 2 & 2,7 \\
\hline Flatfishes & Pleuronectidae & $3.0 \pm 0.6$ & 8 & $1,2,3,4,5$ \\
\hline Flathead sole & Hippoglossoides elassodon & $2.9 \pm 1.4$ & 2 & 5,12 \\
\hline Gadids & Gadidae & $2.2 \pm 0.2$ & 8 & $1,2,4,5,7,10,11$ \\
\hline Haddock & Melanogrammus aeglefinus & 1.4 & 1 & 2 \\
\hline Pacific cod & Gadus macrocephalus & $1.9 \pm 0.1$ & 4 & $1,4,5,8$ \\
\hline Pacific halibut & Hippoglossus stenolepis & 3.9 & 1 & 4 \\
\hline Pacific sandfish & Trichodon trichodon & $5.1 \pm 0.8$ & 2 & $1,8,9$ \\
\hline Pacific tomcod & Microgadus proximus & $2.2 \pm 1.1$ & 3 & $1,5,11$ \\
\hline Pollock & Pollachius virens & 3.0 & 1 & 2 \\
\hline Pricklebacks & Stichaeidae & $3.4 \pm 0.6$ & 5 & 1,7 \\
\hline Rock sole & Lepidopsetta spp. & $3.0 \pm 1.5$ & 3 & $3,8,11$ \\
\hline Silver hake & Merluccius bilinearis & 2.2 & 1 & 2 \\
\hline Yellow Irish lord & Hemilepidotus jordani & 4.7 & 1 & 8 \\
\hline Yellowfin sole & Limanda aspera & 3.1 & 1 & 5 \\
\hline \multicolumn{5}{|l|}{ Intermediate } \\
\hline Walleye pollock & Theragra chalcogramma & $3.0 \pm 0.5$ & 6 & $1,4,5,8,10,11$ \\
\hline \multicolumn{5}{|l|}{ Pelagic } \\
\hline Capelin & Mallotus villosus & $7.6 \pm 1.7$ & 6 & $1,2,5,7,9,10$ \\
\hline Eulachon & Thaleichthys pacificus & $22.5 \pm 6.0$ & 4 & $1,5,8,10$ \\
\hline Herring & Clupea harengus & $10.7 \pm 3.0$ & 2 & 2,7 \\
\hline Mackerel & Scomber scombrus & $9.6 \pm 6.2$ & 2 & 2,6 \\
\hline Northern sand lance $^{\mathrm{a}}$ & Ammodytes dubius & $4.3 \pm 1.4$ & $\begin{array}{l}2 \\
2\end{array}$ & 2,7 \\
\hline Pacific herring & Clupea pallasii & $10.6 \pm 2.1$ & 4 & $1,5,8,10,11$ \\
\hline
\end{tabular}

composition of whole lipid extracts was determined by gas chromatography and mass spectrometry. A $1.0 \mathrm{ml}$ aliquot of lipid extract was trans-esterified by mixing it with Hilditch solution and heating to $80^{\circ} \mathrm{C}$ for $2 \mathrm{~h}$. Fatty acid methyl esters were washed with $5 \% \mathrm{NaCl}$ and extracted in hexane. Purified extracts were evaporated under nitrogen to a volume of $\sim 1 \mathrm{ml}$. Concentrations of 31 fatty acids were measured on a Hewlett Packard 6890 gas chromatograph equipped with a Model 5973 mass selective detector. Concentrations were determined from 5-point calibration curves developed for each fatty acid normalized to a surrogate standard (C19:0), added prior to trans-esterification. Each batch of 20 samples included a method blank, reference sample, and 1 sample randomly selected for duplicate analysis. Sample sizes are summarized in Table 3.

We also analyzed published data to compare absolute EFA content and total lipid content among a broader group of fish species. We are not aware of any papers that compare the absolute fatty acid content of total lipid among species, but papers are available that compare relative fatty acid content of individual lipid classes (e.g. phospholipids, tryacylglycerols, sterols; Saito \& Murata 1998). Differences among species in total lipid content are expected to be expressed almost entirely in differences in tryacylglycerol (TAG) content, while the content of other lipid classes is expected to remain fairly constant (Olsen 1999). We therefore reasoned that differences among species in EFA content that are related to differences in total lipid content would be expressed in terms of EFA contained within TAG. We searched the Science Citation Index Expanded database for the period 1980 to 2004 for papers that (1) compared total lipid content and the proportion of lipid classes among fish species, and (2) presented data on the fatty acid content of individual lipid classes for the same species. Almost all comparable data came from 4 studies of myctophids (Reinhardt \& Van Vleet 1986, Seo et al. 1996, Saito \& Murata 1998, Lea et al. 2002), so we limited our analysis to this family. These 
Table 3. Northeastern Pacific fishes used in comparison of total lipid and essential fatty acid content. Data are mean \pm SD

\begin{tabular}{|lllrrrr}
\hline Common name & Scientific name & $\begin{array}{l}\text { Median } \\
\text { sampling } \\
\text { date }\end{array}$ & $\mathrm{n}$ & $\begin{array}{c}\text { Mean } \\
\text { length } \\
\text { (mm) }\end{array}$ & $\begin{array}{c}\text { Mean } \\
\text { weight } \\
\text { (g) }\end{array}$ & $\begin{array}{c}\text { Mean total } \\
\text { lipid content } \\
\text { (\% wet mass) }\end{array}$ \\
\hline Capelin & Mallotus villosus & 28 November 2001 & 8 & $88 \pm 16$ & $3.8 \pm 2.7$ & $5.1 \pm 1.8$ \\
& & 30 May 2002 & 6 & $105 \pm 10$ & $7.4 \pm 2.0$ & $2.3 \pm 0.5$ \\
Pacific sand lance & Ammodytes hexapterus & 12 September 2001 & 7 & $154 \pm 12$ & $13.7 \pm 3.0$ & $3.7 \pm 0.7$ \\
Pacific hake & Merluccius productus & 29 March 2002 & 19 & $454 \pm 34$ & $620 \pm 166$ & $7.0 \pm 1.9$ \\
& & 12 September 2001 & 10 & $456 \pm 56$ & $619 \pm 237$ & $5.3 \pm 0.9$ \\
Pacific herring & Clupea pallasii & 11 September 2001 & 20 & $166 \pm 29$ & $53 \pm 24$ & $13.3 \pm 5.2$ \\
Walleye pollock & Theragra chalcogramma & 2 April 2002 & 7 & $121 \pm 31$ & $17 \pm 13$ & $4.4 \pm 3.1$ \\
& & 28 November 2001 & 47 & $316 \pm 160$ & $439 \pm 496$ & $4.0 \pm 1.7$ \\
& & & 5 & $224 \pm 31$ & $83 \pm 39$ & $2.7 \pm 2.2$ \\
\hline
\end{tabular}

studies compared total lipid content and the proportion of different lipid classes among 29 species from a variety of regions (tropical, temperate, sub-arctic, Antarctic) and depths (20 to $1200 \mathrm{~m}$ ). Several species were measured in different areas and with different total lipid content ( $\mathrm{n}=44$ measurements). Saito \& Murata (1998) also presented data on the relative fatty acid content of neutral storage lipids for 10 species. With these data we compared fishes with different levels of total lipid in terms of (1) content of phospholipids (PL) and TAG, the dominant lipid classes, and (2) absolute content of EPA and DHA within TAG. Species that accumulate wax esters as storage lipids were excluded from analysis, and data derived using the Bligh \& Dyer method of lipid extraction were corrected for comparison with the Folch method (see 'Lipid content and population trajectories' section). Using data on the relative fatty acid content of TAG from different species (Salto \& Murata 1998), we used the fact that each TAG molecule contains 3 fatty acids to calculate the molar concentration of each fatty acid in a hypothetical TAG sample, and then used the molecular weight of each fatty acid to calculate the absolute content (\% total mass) of EFA contained within TAG (Table 4). Lipid and EFA content were arcsine-transformed before analysis to satisfy assumptions of normality. We set $\alpha=$ 0.05 , and means are presented as \pm SE unless otherwise noted.

\section{RESULTS}

Average lipid content of pelagic species in our literature survey $(10.9 \pm 2.5 \%)$ was 3 times that of demersal species (excluding family estimates; $3.6 \pm 0.5 \%, t_{19}=$ 4.17, $\mathrm{p}=0.0005$, Table 2). In all 4 examples we found significant differences in the lipid content of species that increased and decreased in abundance (2-sample $t$-tests: Bering Sea 1970s: $t_{6}=3.20, \mathrm{p}=0.02$; Gulf of Alaska 1970s: $t_{13}=2.17, \mathrm{p}=0.049$; North Sea 1960s: $t_{4}=$

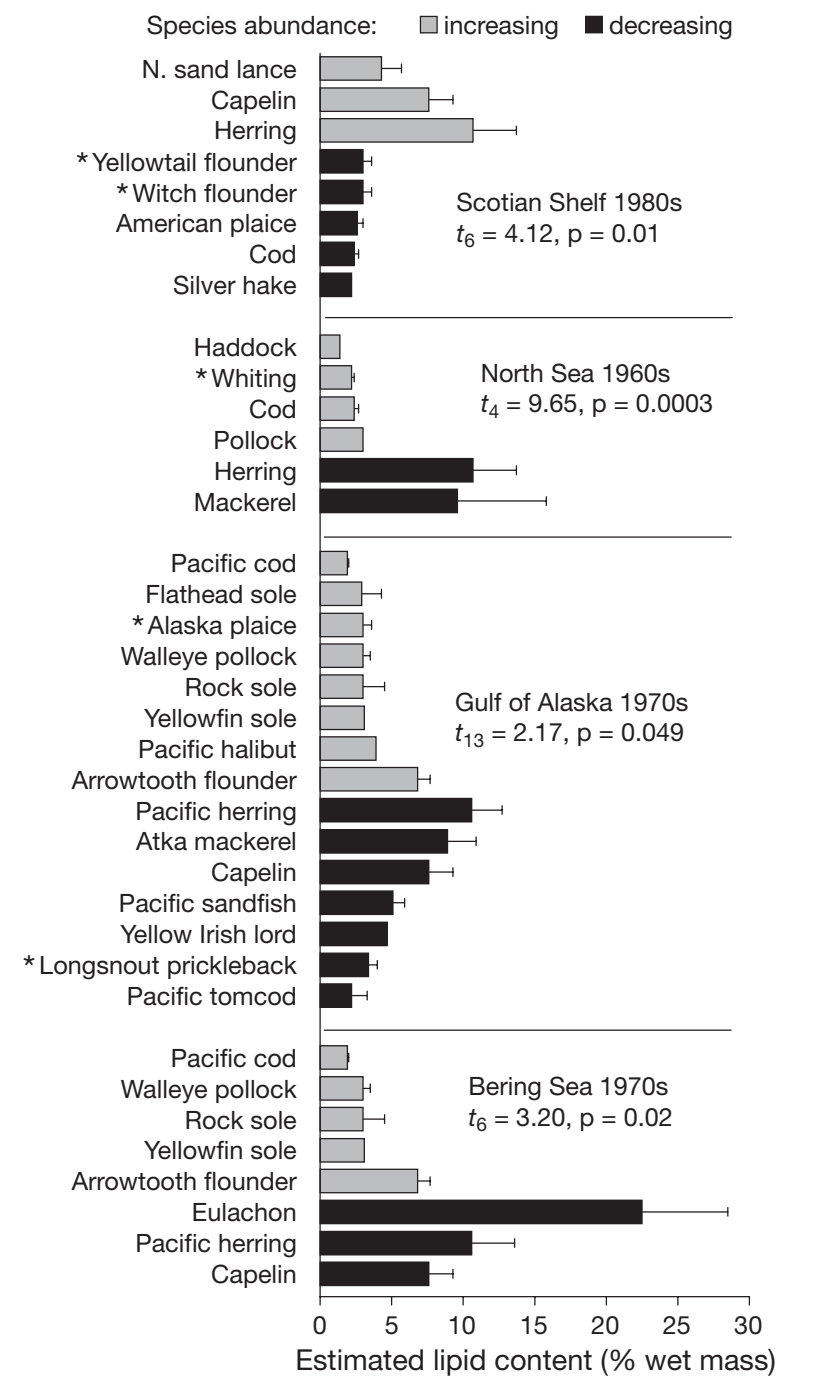

Fig. 1. Opposite population trajectories in lipid-rich and lipidpoor species following climate regime shifts: analysis of previously published data on fish population trajectories (Table 1) and lipid content (Table 2). In each instance lipid content was significantly different between groups that increased and decreased in abundance. * Indicates lipid data estimated from family mean, error bars + SE 
Table 4. Calculations used to derive absolute content (\% total mass) of fatty acids contained in triacyglycerol (TAG) using published data on relative fatty acid content (\% total fatty acid mass): example using Ceratoscoperus warmingi (Saito \& Murata 1998). Relative content (mmol): relative content / molecular weight; number of moles in a hypothetical sample of TAG = total moles of fatty acid / 3. Mass (mg): moles / (molecular weight -17); assumes fatty acid present as RCO (less $\mathrm{OH}$ to account for $\mathrm{H}_{2} \mathrm{O}$ lost when ester bond is formed). \% TAG mass: mass / (sum fatty acid mass + number of tryglycerol moles $\times 89$ ); assumes glycerol is present as $\mathrm{C}_{3} \mathrm{H}_{5} \mathrm{O}_{3}$ to account for $\mathrm{H}$ lost during ester bond formation. Absolute content ( $\%$ total mass): \% TAG mass $\times 88.5 \%$

(\% TAG content of lipid for C. warmingi) $\times 14.3 \%$ (\% lipid content of total mass for C. warmingi)

\begin{tabular}{|c|c|c|c|c|c|c|c|}
\hline Fatty acid & $\begin{array}{l}\text { Molecular } \\
\text { weight } \\
\left(\mathrm{g} \mathrm{mol}^{-1}\right)\end{array}$ & $\begin{array}{c}\text { Relative content } \\
\text { (\% total fatty acid mass } \\
\text { contained in TAG) }\end{array}$ & $\begin{array}{l}\text { Relative } \\
\text { content } \\
\text { (mmol) }\end{array}$ & $\begin{array}{c}\text { Molar } \\
\text { concentration } \\
\text { (\% of fatty acid total) }\end{array}$ & $\begin{array}{l}\text { Mass } \\
(\mathrm{mg})\end{array}$ & $\begin{array}{c}\% \text { TAG } \\
\text { mass }\end{array}$ & $\begin{array}{c}\text { Absolute } \\
\text { content } \\
\text { (\% total mass) }\end{array}$ \\
\hline 14:0 & 228 & 2.5 & 0.109 & 3.2 & 23.1 & 2.29 & 0.29 \\
\hline $15: 0$ & 242 & 0.4 & 0.017 & 0.5 & 3.7 & 0.37 & 0.05 \\
\hline $16: 0$ & 256 & 21.5 & 0.838 & 24.3 & 200.7 & 19.88 & 2.52 \\
\hline $17: 0$ & 270 & 0.6 & 0.022 & 0.6 & 5.6 & 0.56 & 0.07 \\
\hline $18: 0$ & 284 & 6.9 & 0.243 & 7.0 & 64.9 & 6.42 & 0.81 \\
\hline 20:0 & 313 & 0.2 & 0.006 & 0.2 & 1.9 & 0.19 & 0.02 \\
\hline $14: 1$ & 226 & 0.1 & 0.004 & 0.1 & 0.9 & 0.09 & 0.01 \\
\hline $16: 1 \mathrm{n}-7$ & 254 & 4.0 & 0.157 & 4.6 & 37.3 & 3.70 & 0.47 \\
\hline $16: 1 n-5$ & 254 & 0.1 & 0.004 & 0.1 & 0.9 & 0.09 & 0.01 \\
\hline $17: 1$ & 268 & 0.2 & 0.007 & 0.2 & 1.9 & 0.19 & 0.02 \\
\hline $18: 1 n-9$ & 282 & 31.2 & 1.105 & 32.0 & 293.2 & 29.04 & 3.68 \\
\hline $18: 1 n-7$ & 282 & 3.5 & 0.124 & 3.6 & 32.9 & 3.26 & 0.41 \\
\hline $18: 1 n-5$ & 282 & 0.1 & 0.004 & 0.1 & 0.9 & 0.09 & 0.01 \\
\hline $20: 1 n-11$ & 311 & 0.3 & 0.010 & 0.3 & 2.8 & 0.28 & 0.04 \\
\hline $20: 1 n-9$ & 311 & 2.7 & 0.087 & 2.5 & 25.5 & 2.53 & 0.32 \\
\hline 20:1n-7 & 311 & 0.2 & 0.006 & 0.2 & 1.9 & 0.19 & 0.02 \\
\hline $22: 1 n-11$ & 339 & 0.6 & 0.018 & 0.5 & 5.7 & 0.56 & 0.07 \\
\hline $22: 1 n-9$ & 339 & 0.5 & 0.015 & 0.4 & 4.7 & 0.47 & 0.06 \\
\hline $22: 1 n-7$ & 339 & 0.1 & 0.003 & 0.1 & 0.9 & 0.09 & 0.01 \\
\hline $24: 1 n-9$ & 367 & 0.4 & 0.011 & 0.3 & 3.8 & 0.38 & 0.05 \\
\hline $16: 2 n-6$ & 252 & 0.9 & 0.036 & 1.0 & 8.4 & 0.83 & 0.11 \\
\hline $18: 2 n-6$ & 280 & 0.9 & 0.032 & 0.9 & 8.5 & 0.84 & 0.11 \\
\hline $20: 3 n-6$ & 306 & 0.9 & 0.029 & 0.9 & 8.5 & 0.84 & 0.11 \\
\hline $18: 3 n-3$ & 278 & 0.6 & 0.022 & 0.6 & 5.6 & 0.56 & 0.07 \\
\hline $18: 4 n-3$ & 276 & 0.8 & 0.029 & 0.8 & 7.5 & 0.74 & 0.09 \\
\hline $20: 4 n-3$ & 304 & 1.0 & 0.033 & 1.0 & 9.4 & 0.94 & 0.12 \\
\hline C20:5 (n-3). EPA & 302 & 5.8 & 0.192 & 5.6 & 54.7 & 5.42 & 0.69 \\
\hline $22: 5 n-3$ & 331 & 1.1 & 0.033 & 1.0 & 10.4 & 1.03 & 0.13 \\
\hline C22:6 (n-3). DHA & 328 & 8.5 & 0.259 & 7.5 & 80.6 & 7.98 & 1.01 \\
\hline Total & & & 3.454 & 100.0 & 907.3 & 89.85 & 11.37 \\
\hline
\end{tabular}

9.65, $\mathrm{p}=0.0003 ;$ Scotian Shelf 1980s: $t_{6}=4.12, \mathrm{p}=0.01$; Fig. 1). All 4 rejections of the null hypothesis were retained under false discovery rate control. The chance of rejecting the null hypothesis 4 times, given no difference in lipid content between species increasing and decreasing in abundance, is the product of the 4 $\alpha$ values (adjusted for false discovery rate control), or $\mathrm{p}=0.0000006$. Because eulachon contain uniquely low levels of EPA and DHA (Iverson et al. 2002), we assume that this species is likely not affected by restricted EFA availability in the same way as other lipid-rich species. We therefore repeated analysis for the Bering Sea excluding this species and obtained similar results $\left(t_{5}=3.43, \mathrm{p}=0.02\right)$. On average, the lipid content of the higher-lipid group following a climate shift was $330 \pm 60 \%$ that of the lower-lipid group. In every case, the resulting relatively lipid-poor or lipidrich fish community persisted at a decadal time scale
(Cushing 1980, Anderson \& Piatt 1999, Hunt et al. 2002, Beaugrand 2004, Choi et al. 2004).

Total lipid content of individual fish from the northeast Pacific ranged from 1.0 to $28.9 \%$ (wet mass). EPA and DHA content were affected by both species identity (MANOVA: Wilks' $\lambda_{8,244}=0.56, \mathrm{p}<0.0001$ ) and total lipid content (MANOVA: Wilks' $\lambda_{2,122}=0.28, \mathrm{p}<$ $0.0001)$. A general linear model including species identity and lipid content as explanatory variables showed strong effects on both EPA content $\left(\mathrm{R}^{2}=0.76, F_{5,123}=\right.$ $76.60, \mathrm{p}<0.0001)$ and DHA content $\left(\mathrm{R}^{2}=0.82, F_{5,123}=\right.$ 114.74, p < 0.0001; Table 5). The content of both EFA increased as a function of total lipid content (Fig. 2).

Total lipid content of individual myctophids from published studies ranged from 0.5 to $46.3 \%$ (wet mass). As expected, variability in total lipid content had no significant effect on PL content (linear regression: $\mathrm{n}=44, \mathrm{r}^{2}=0.05, \mathrm{p}=0.21$; Fig. 3a), but was tightly 
- Capelin $\square$ Hake $\Delta$ Herring $\diamond$ Pollock $\times$ Sand lance
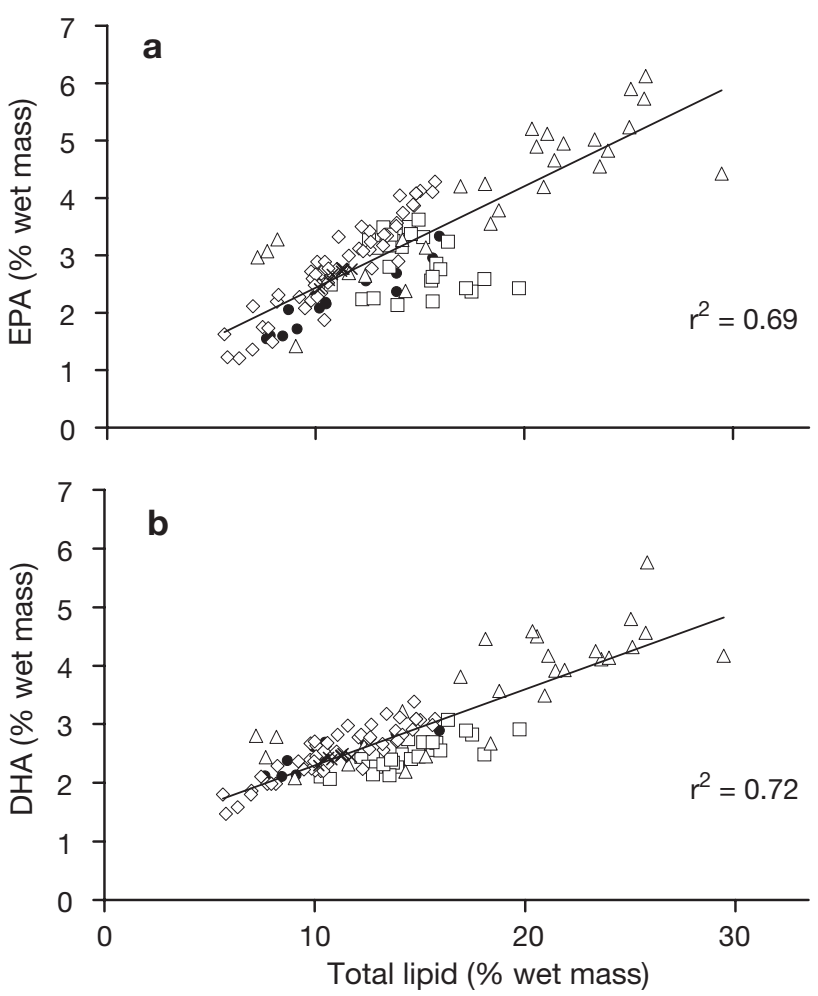

Fig. 2. The relationship between total lipid content and content of 2 essential fatty acids (EFAs) for 5 species of fish from the northeast Pacific: (a) EPA, eicosapentanoic acid; (b) DHA, docosahexanoic acid. MANOVA demonstrated an overall effect of both species identity and lipid content on the content of the 2 EFAs ( $p<0.0001)$. Plotted data have been arcsine transformed

linked with increased TAG content (linear regression: $\mathrm{n}=44, \mathrm{r}^{2}=0.98, \mathrm{p}<0.0001$; Fig. 3b). Fishes with higher total lipid content also had higher absolute content of TAG-contained EPA (linear regression: $\mathrm{n}=10, \mathrm{r}^{2}=$ 0.93, p < 0.0001; Fig. 3c) and DHA (linear regression: $\mathrm{n}=10, \mathrm{r}^{2}=0.83, \mathrm{p}<0.0001$; Fig. 3d). MANOVA showed a significant overall effect of lipid content on TAG, EPA and DHA content (Wilks' $\lambda_{3,6}<0.0001, \mathrm{p}<0.0001$ ).
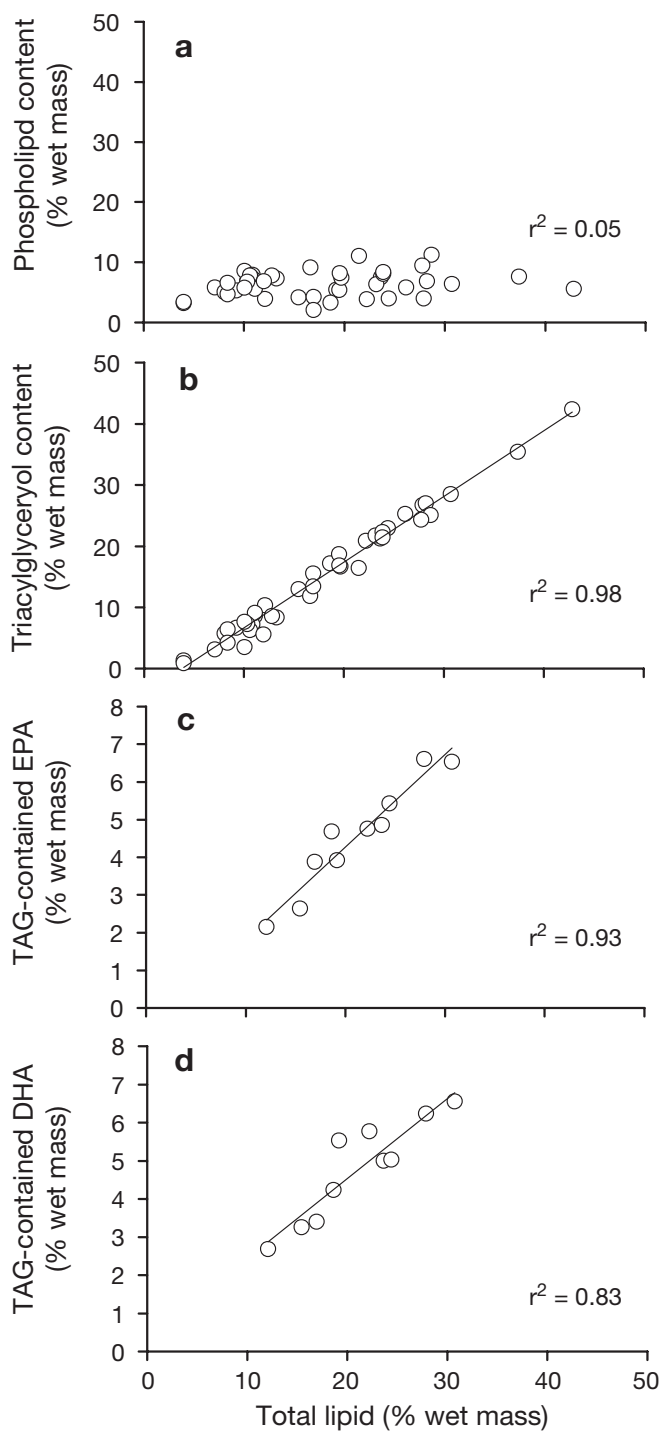

Fig. 3. Increases in tryacylglycerols (TAG) and TAG-contained essential fatty acids with increasing lipid content for 29 species of myctophids. The relationship between total lipid content and (a) structural phospholipids (PL), (b) neutral TAG, (c) TAG-contained eicosapentanoic acid (EPA), (d) TAGcontained docosahexanoic acid (DHA); data from Reinhardt \& Van Vleet (1986), Seo et al. (1996), Saito \& Murata (1998), and Lea et al. (2002). See Table 4 for calculation details. Plotted data have been arcsine transformed

\section{DISCUSSION}

We found that transitions in boreal fish communities following climate regime shifts produced opposite population trajectories in lipid-rich and lipid-poor species. Estimates of mean species lipid content are complicated by high intra-species variability (Anthony et al. 2000, Wanless et al. 2005) and a lack of comprehensive data for most species (Logerwell \& Schaufler 2005).
Table 5. Effect of total lipid content on EPA and DHA content in 5 northeast Pacific fish species: GLM results. MANOVA demonstrated a significant overall effect of species and lipid content $(p<0.0001)$

\begin{tabular}{|llrcrc|}
\hline Response variable & Factor & df & MSE & $F$ & p \\
\hline EPA (\% wet mass) & Species & 4 & 2.19 & 8.87 & $<0.001$ \\
& Lipid (\% wet mass) & 1 & 49.22 & 199.78 & $<0.001$ \\
& Error & 123 & 0.25 & & \\
DHA (\% wet mass) & Species & 4 & 1.58 & 17.27 & $<0.001$ \\
& Lipid (\% wet mass) & 1 & 25.15 & 275.28 & $<0.001$ \\
& Error & 123 & 0.09 & & \\
\hline
\end{tabular}


However, existing data are adequate to demonstrate consistent species differences in lipid content (Iverson et al. 2002) and our inference is strengthened by our ability to draw on multiple studies for most species used in our analysis (Table 2). As in other studies (Anthony et al. 2000, Iverson et al. 2002), we found that lipid content was on average about 3 times greater in pelagic-feeding species than in demersal species. Every example of community transition that we found involved a switch between demersal and pelagic species, or vice versa, but there was no consistent correlation between temperature change and the nature of community transition: colder temperatures were associated with higher abundance of pelagic fishes in 3 ecosystems, but with higher abundance of demersal fishes in the North Sea (Table 1). This observation argues against the simple relationship between temperature and fish community EFA content that is suggested by patterns of higher EFA production in cold ecosystems (Olsen 1999, Dalsgaard et al. 2003), and underscores the complexity of interactions between the physical environment and community biochemistry.

Transitions in the Bering Sea and Gulf of Alaska were part of ecological change in the Pacific following the 1976-1977 shift in the Pacific Decadal Oscillation (Anderson \& Piatt 1999, Chavez et al. 2003). Decadalscale climate variability in the North Atlantic apparently plays a similar role in producing sudden transitions in ecosystems (Beaugrand 2004), although trophic cascades following over-fishing of high trophic level demersal fishes have also contributed to community transitions in the North Atlantic (Choi et al. 2004). The Scotian Shelf community transition is believed to be the result of over-fishing and, to a lesser extent, decadal-scale climate variability (Choi et al. 2004). Multiple causality is likely the rule for community transitions in shelf ecosystems, as alternate stable states in much simpler lake ecosystems are the result of interactions between multiple mechanisms (Scheffer et al. 2001). Data are not available to directly compare absolute EFA content between demersal and pelagic fishes, but a correlation between lipid content and EFA content (Figs. 2 \& 3) suggests that lipid-rich and lipidpoor fish communities can be viewed as EFA-rich and EFA-poor, respectively. Although alternate states have been identified in many ecosystems (Scheffer et al. 2001), we are not aware of previous observations of alternate states in community physiological properties such as lipid and fatty acid content.

Although the sum content of all fatty acids is correlated with total lipid content in fishes (Ahlgren et al. 1996), EFAs are the only lipid constituents that cannot be synthesized by animals, and so have a unique potential to exert bottom-up control on animal popula- tions (Müller-Navarra 1995, Brett \& Müller-Navarra 1997). Correlation between lipid content and EFA content therefore suggests a possible mechanistic link between EFA limitation and fish community lipid content. However, caution should be taken when interpreting correlations between lipid and EFA content in terms of species-specific EFA requirements. The differences among species in lipid content derive primarily from differences in the amount of storage lipids (Olsen 1999). The relationship between EFA and lipid that we identified is therefore driven by variation in the EFA content of storage lipid, but the degree to which EFA found in lipid reserves reflects EFA requirements is unknown. In addition, EPA, DHA and other EFA compete with one another in various biochemical reactions, so that EFA ratios, in addition to the absolute availability of individual EFA, are important considerations in the diets of marine organisms (Tocher 2003). Despite these caveats, the existing data do not lead us to reject the notion that species with high lipid content have high EFA requirements. Opposite population trajectories in lipid-rich and lipid-poor species and higher EFA contents in lipid-rich species lead us to infer that variation in EFA availability might contribute to community transitions. While limited availability of DHA or EPA limits zooplankton production (Jónasdóttir et al. 1995, Arendt et al. 2005), and changes in EFA production may cause disease in fish populations (Ahlgren et al. 2005), mechanistic links between EFA availability and fish population trajectories remain speculative. In particular, increased EFA availability would have to confer an unexplained advantage on species with high EFA requirements over those that are productive when EFA supplies are low. Lipid biochemistry is extremely complex, and the analysis presented here is only intended as an initial comparison of possible differences in fish EFA requirements. Much more research into the nature of these requirements is needed before ecological implications can be elucidated.

\section{Climate regime shifts and EFA availability}

No data are available on regime shift effects on EFA production, but an extensive literature on variability in EFA production suggests that such effects could be expected. Laboratory and field studies have revealed consistent differences in EFA production by dominant phytoplankton groups. Diatoms are typically rich in EPA and dinoflagellates and coccolithophores are typically rich in DHA (Dalsgaard et al. 2003). Variability in EFA production within taxa also exists, although this is generally less than variability among taxa (Dalsgaard et al. 2003). Within-taxa variability in EFA production 
is tightly linked to physical processes, including water temperature, light and nutrient availability, stratification and mixed layer depth (Dalsgaard et al. 2003).

Changes in physical oceanography could therefore change EFA production either by changing phytoplankton species composition or by changing EFA production within phytoplankton taxa. Climate regime shifts drive phytoplankton communities between alternate species assemblages (Karl et al. 2001), and regime shifts involve changes in physical properties like temperature, upwelling of nutrients and mixed-layer depth (Chavez et al. 2003) that can be expected to impact EFA production within phytoplankton taxa. Order of magnitude variability in seston EFA content has been observed in high-latitude systems at interannual and regional scales (Skerratt et al. 1995), and spatial variability in phytoplankton EFA production produces variability in the EFA content of both zooplankton and fish (St. John \& Lund 1996). One of the best-studied examples of changing EFA production in response to environmental change comes from the Baltic Sea, where eutrophication has shifted phytoplankton dominance from diatoms to flagellates, apparently resulting in changes in EFA ratios throughout the food web, and possibly leading to a chronic reproductive disease in salmon (Salmo salar; Ahlgren et al. 2005). Given the extensive knowledge of environmental control of EFA production, it seems reasonable to accept that climate regime shifts might change EFA availability throughout marine food webs. The compelling question is whether such changes could be expected to reorganize fish communities.

\section{Could EFA availability structure fish communities?}

Variability in the EFA content of freshwater phytoplankton communities produces variability in the EFA content of fish (Ahlgren et al. 1996), even though many freshwater fishes are able to produce EPA and DHA by elongating and desaturating $\alpha$-linolenic acid (Dalsgaard et al. 2003). Marine fishes either cannot produce EPA and DHA from $\alpha$-linolenic acid, or do so less efficiently than freshwater fishes (Kanazawa et al. 1979), suggesting a strong possibility for bottom-up control of EFA levels in marine systems. Indeed, the fatty acid composition of marine fish is well known to reflect the fatty acid content of their diet, and, ultimately, of local phytoplankton (St. John \& Lund 1996). However, similarity between fish and phytoplankton EFA signatures does not necessarily imply EFA limitation. Availability of EFA is much higher in marine systems, particularly at high latitudes, than in freshwater systems (Olsen 1999), and the reduced ability of marine fishes to convert precursors into EPA and DHA has been interpreted as evidence that these EFA are not limiting in marine systems.

Although EFA availability is generally high in marine settings, it is also highly variable (see above). This variability suggests the possibility of at least occasional EFA limitation, and field studies have demonstrated EFA limitation of egg production and hatching success in copepods (Jónasdóttir et al. 1995, Arendt et al. 2005). Thus, EFA restriction can limit reproduction of marine invertebrates in the wild, and there are similar effects on fish. Natural variability in EFA content of common wolffish Anarhichas lupus eggs correlates with hatching and survival rates (Halfyard et al. 2001), and field-collected Atlantic herring Clupea harengus larvae show order of magnitude variability in EFA and lipid content that correlates with dietary EFA restriction and poor nutritional condition (Fraser et al. 1987). Larvae of other fish species show similar variability in lipid content that correlates with diet quality (Lochmann et al. 1995). The potential for EFA limitation is likely highest for larval and juvenile fish because rapid growth produces high EFA requirements (Tocher 2003), and because EFA content amplifies with trophic level so that planktivorous diets are typically lower in EFA than piscivorous diets (Brett \& Müller-Navarra 1997). Because grazers are able to ensure an adequate supply of EFA through selective feeding, limitation of zooplankton is considered most likely during monospecific blooms of EFA-deficient phytoplankton (Brett \& Müller-Navarra 1997), and planktonic larval fish might be similarly susceptible to limitation during monospecific blooms. There are no available data that would allow comparisons of early life-history lipid and EFA requirements among species involved in community reorganizations (Table 2). However, lipid and EFA content data from 4 marine fish species (Pacific herring, Pacific sand lance, Pacific tomcod Microgadus proximus and walleye pollock) show that total lipid content within species is highly correlated between adult and juvenile stages, and species with higher juvenile lipid content also contain reduced DHA:EPA ratios (Iverson et al. 2002), suggesting a mechanism by which changing food web DHA:EPA ratios might differentially impact lipid-rich and lipid-poor species.

The EFA limitation hypothesis also has implications for the fate of piscivorous marine mammals and seabirds under different climate regimes. Reduced availability of lipid-rich fishes may reduce the energy content of seabird nestling diets, resulting in reduced nestling growth rates and lipid reserves, increased levels of corticosterone stress hormones, and reduced reproductive success (Wanless et al. 2005), suggesting a mechanism by which EFA restriction of community lipid content might impact piscivores. 
The 4 examples of community reorganization that we utilized in this paper all involved shifts between pelagic and demersal communities (Table 1). We recognize that the alternate EFA-content states that these shifts imply might simply be a side effect of other ecological processes, such as predation, that differentially impact pelagic and demersal communities. However, growing awareness of the role played by EFA in aquatic ecosystems (Brett \& Müller-Navarra 1997, Ahlgren et al. 2005), observations of EFA restriction of zooplankton reproduction (Jónasdóttir et al. 1995, Arendt et al. 2005) and correlation between EFA restriction and reduced nutritional condition in larval fishes (Fraser et al. 1987) all suggest a novel path of inquiry into the links between the mechanistic role of EFA in aquatic food webs, climate regime shifts and the structure of fish communities.

Acknowledgements. We thank R. Foy for sharing unpublished data, B. Malley for library assistance, and A. Abookire, L. Ciannelli, J. Duffy-Anderson, R. Otto and 4 anonymous reviewers for helpful comments on earlier drafts of this paper. This research is contribution FOCI-0588 to NOAA's FisheriesOceanography Coordinated Investigations.

\section{LITERATURE CITED}

Ahlgren G, Sonesten L, Boberg M, Gustafsson IB (1996) Fatty acid content of some freshwater fish in lakes of different trophic levels - a bottom-up effect? Ecol Freshw Fish 5: $15-27$

Ahlgren G, Nieuwerburgh L, Wänstrand I, Pedersén M, Boberg M, Snoeijs P (2005) Imbalance of fatty acids in the base of the Baltic Sea food web - a mesocosm study. Can J Fish Aquat Sci 62:2240-2253

Anderson PJ, Piatt JF (1999) Community reorganization in the Gulf of Alaska following ocean climate regime shift. Mar Ecol Prog Ser 189:117-123

Anthony JA, Roby DD, Turco KR (2000) Lipid content and energy density of forage fishes from the northern Gulf of Alaska. J Exp Mar Biol Ecol 248:53-78

Arendt KE, Jónasdóttir SH, Hansen PJ, Gartner S (2005) Effects of dietary fatty acids on the reproductive success of the calanoid copepod Temora longicornis. Mar Biol 146: 513-530

Beaugrand G (2004) The North Sea regime shift: evidence, causes, mechanisms and consequences. Prog Oceanogr 60:245-262

Brett MT, Müller-Navarra DC (1997) The role of highly unsaturated fatty acids in aquatic food web processes. Freshw Biol 38:483-499

Budge SM, Iverson SJ, Bowen WD, Ackman RG (2002) Amongand within-species variability in fatty acid signatures of marine fish and invertebrates on the Scotian Shelf, Georges Bank, and southern Gulf of St. Lawrence. Can J Fish Aquat Sci 59:886-898

Chavez FP, Ryan J, Lluch-Cota SE, Niquen M (2003) From anchovies to sardines and back: multidecadal change in the Pacific Ocean. Science 299:217-221

Choi JS, Frank KT, Leggett WC, Drinkwater K (2004) Transition to an alternate state in a continental shelf ecosystem. Can J Fish Aquat Sci 61:505-510

Cushing DH (1980) The decline of the herring stocks and the
Gadoid outburst. J Cons 39:70-81

Cushing DH (1984) The Gadoid outburst in the North Sea. J Cons 41:159-166

Dalsgaard J, St John M, Kattner G, Muller-Navarra D, Hagen W (2003) Fatty acid trophic markers in the pelagic marine environment. Adv Mar Biol 46:225-340

Fraser A, Sargent J, Gamble J, MacLachlan P (1987) Lipid class and fatty acid composition as indicators of the nutritional condition of larval Atlantic herring. Am Fish Soc Symp 2:129-143

Halfyard L, Parrish C, Watkins J, Jauncey K (2001) Fatty acid and amino acid profiles of eggs from the common wolffish, Anarhichas lupus. Bull Aquat Assoc Can 4:60-63

Hunt GL, Stabeno P, Walters G, Sinclair E, Brodeur RD, Napp JM, Bond NA (2002) Climate change and control of the southeastern Bering Sea pelagic ecosystem. Deep-Sea Res Part II 49:5821-5853

Iverson SJ, Lang SLC, Cooper MH (2001) Comparison of the Bligh and Dyer and Folch methods for total lipid determination in a broad range of marine tissue. Lipids 36 : $1283-1287$

Iverson SJ, Frost KJ, Lang SLC (2002) Fat content and fatty acid composition of forage fish and invertebrates in Prince William Sound, Alaska: factors contributing to among and within species variability. Mar Ecol Prog Ser 241:161-181

Jónasdóttir SH, Fields D, Pantoja S (1995) Copepod egg production in Long Island Sound, USA, as a function of the chemical composition of seston. Mar Ecol Prog Ser 119:87-98

Kanazawa A, Teshima S, Ono K (1979) Relationship between essential fatty acid requirements of aquatic animals and the capacity for bioconversion of linolenic acid to highly unsaturated fatty acids. Comp Biochem Physiol B 63: 295-298

Karl DM, Bidigare RR, Letelier RM (2001) Long-term changes in plankton community structure and productivity in the North Pacific Subtropical Gyre: the domain shift hypothesis. Deep-Sea Res Part II 48:1449-1470

Kirsch PE, Iverson SJ, Bowen WD, Kerr SR, Ackman RG (1998) Dietary effects on the fatty acid signature of whole Atlantic cod (Gadus morhua). Can J Fish Aquat Sci 55: $1378-1386$

Lawson J, Magalhães A, Miller E (1998) Important prey species of marine vertebrate predators in the northwest Atlantic: proximate composition and energy density. Mar Ecol Prog Ser 164:13-20

Lea MA, Nichols PD, Wilson G (2002) Fatty acid composition of lipid-rich myctophids and mackerel icefish (Champsocephalus gunnari) - Southern ocean food-web implications. Polar Biol 25:843-854

Lochmann SE, Maillet GL, Frank KT, Taggart CT (1995) Lipid class composition as a measure of nutritional condition in individual larval Atlantic cod (Gadus morhua). Can J Fish Aquat Sci 52:1294-1306

Logerwell E, Schaufler L (2005) New data on proximate composition and energy density of Steller sea lion (Eumetopias jubatus) prey fills seasonal and geographic gaps in existing information. Aquat Mamm 31:62-82

Mueter FJ, Norcross BL (2000) Changes in species composition of the demersal fish community in nearshore waters of Kodiak Island, Alaska. Can J Fish Aquat Sci 57:1169-1180

Müller-Navarra D (1995) Evidence that a highly unsaturated fatty acid limits Daphnia growth in nature. Arch Hydrobiol 132:297-307

Olsen Y (1999) Lipids and essential fatty acids in aquatic food webs: what can freshwater ecologists learn from mariculture? In: Arts M, Wainman B (eds) Lipids in freshwater ecosystems. Springer, New York 
Payne SA, Johnson BA, Otto RS (1999) Proximate composition of some north-eastern Pacific forage fish species. Fish Oceanogr 8:159-177

Reinhardt S, Van Vleet E (1986) Lipid composition of twentytwo species of Antarctic midwater zooplankton and fish. Mar Biol 91:149-159

Saito H, Murata M (1998) Origin of the monoene fats in the lipid of midwater fishes: relationship between the lipids of myctophids and those of their prey. Mar Ecol Prog Ser 168:21-33

Scheffer M, Carpenter S, Foley J, Folke C, Walker B (2001) Catastrophic shifts in ecosystems. Nature 413:591-596

Seo HS, Endo Y, Fujimoto K, Watanabe H, Kawaguchi K (1996) Characterization of lipids in myctophid fish in the subarctic and tropical Pacific Ocean. Fish Sci 62:447-453

Skerratt JH, Nichols PD, McMeekin TA, Burton H (1995) Seasonal and interannual changes in planktonic biomass and community structure in eastern Antarctica using signature lipids. Mar Chem 51:93-113

Editorial responsibility: Howard I. Browman (Associate Editor-in-Chief), Storebø, Norway
St. John MA, Lund T (1996) Lipid biomarkers: linking the utilization of frontal plankton biomass to enhanced condition of juvenile North Sea cod. Mar Ecol Prog Ser 131:75-85

Tocher DR (2003) Metabolism and functions of lipids and fatty acids in teleost fish. Rev Fish Sci 11:107-184

Verhoeven K, Simonsen K, McIntyre L (2005) Implementing false discovery rate control: increasing your power. Oikos 108:643-647

Vollenweider J (2005) Variability in Steller sea lion (Eumetopias jubatus) prey quality in southeastern Alaska. MS thesis, University of Alaska, Fairbanks, AK

Wanless S, Harris M, Redman P, Speakman J (2005) Low energy values of fish as a probable cause of a major seabird breeding failure in the North Sea. Mar Ecol Prog Ser 294:1-8

Worthy G, Miculka T (1997) Proximate composition and fatty acid signatures of selected forage fish species in Prince William Sound, Alaska. Exxon Valdez Oil Spill Trustee Council, Restoration Project 95121. Anchorage, AK

Submitted: October 25, 2005; Accepted: February 8, 2006 Proofs received from author(s): March 25, 2006 